\title{
DOSE DEPENDENT BIOLOGICAL EFFECTS OF IDARUBICIN IN HL-60 CELLS: ALTERATIONS OF THE CELL-CYCLE AND APOPTOSIS
}

\author{
Martina Mareková ${ }^{1}$, Jiřina Vávrová ${ }^{2}$, Doris Vokurková ${ }^{3}$
}

Charles University in Prague, Faculty of Medicine in Hradec Králové: Department of Medical Biochemistry ${ }^{1}$; Purkyně Military Medical Academy, Hradec Králové: Institute of Radiobiology and Immunology²; University Teaching Hospital in Hradec Králové: Institute of Clinical Immunology and Allergology ${ }^{3}$

Summary: TP-53 deficient cells of human leukaemia HL-60 die by massive apoptosis after treatment by high (50-100 nmol/1) doses of DNA damaging agent Idarubicin, regardless of the cell-cycle phase, in which they are affected. In contrary, after relatively low dose $10 \mathrm{nmol} / 1$ the cells die after cell-cycle arrest in $\mathrm{G}_{2}$ phase. The results show, that apoptosis induced by idarubicin could appear independently of the cell-cycle phase and that period in which apoptosis is observed is related to the dose of Idarubicin.

Key words: HL-60; Idarubicin; Apoptosis; $G_{2}$ cell-cycle arrest

\section{Introduction}

Acute myeloid leukaemia (AML) accounts for over $80 \%$ of all adult acute leukaemias (7) and is a characterised by a clonal expansion of immature myeloid cells in all haematopoietic tissues. Many patients progress to AML from preleukaemic myelodysplastic syndrome (MDS) or from chronic myelogenous leukaemia (CML). AMLs show varied morphologic, cytochemic, immunologic and cytogenetic characteristics and varied sensitivity to conventional chemotherapeutic regimes. Sixty percent to $70 \%$ of patients with de novo AML initially achieve complete remission. However, the majority of these patients relapse and eventually die of the disease. The first described and best characterized mechanism of resistance is $\mathrm{mdr} 1$ gene product, P-glycoprotein. This molecule spans the cell membrane and act as an efflux pump for toxins, including chemotherapy drugs such as anthracyclines, vinca alkaloids and topoisomerase II inhibitors. The biological bases of drug resistance and relapse in AML are not understood and prognoses are still largely based on descriptive parameters. Several lines of evidence indicated that apoptosis plays roles in responses of AML patients to chemotherapy. Aldrige and Radford (1) showed that differences between human haematopoietic cell lines, in the rate of induction of apoptosis after irradiation were generally related to the functioning of cell cycle checkpoints. Whereas the rapidly dying and radiosensitive HSB-2 cell line underwent apoptosis at different points in the cell cycle, the more slowly dying cell lines showed a variety of cell cycle arrest profiles and initiated apoptosis after accumulation of cells in the $G_{2}$ phase. HL-60 cells showed a markedly longer $G_{2}$ arrest that correlated with their greater radioresistance. The result suggest that the total length of time available for DNA damage repair (regard less of whether this time occures as arrest in $G_{1}, S$ or $G_{2}$ ), prior to potential activation of apoptosis, is a critical determinant of radiosensitivity in human haematopoietic cell lines.

The mode of induction of apoptosis is dependent upon the cell type and the type and concentration of cytostatic drug used. Three different routes to the induction of apoptosis, presumably reflecting differences in nature of the initiating lesion, were identified for lymphoid and myeloid cell lines: 1. Rapid interphase apoptosis, where death occurred soon after death stimulus and in different phases of cell cycle. 2. Delayed interphase apoptosis, where death occurred following arrest in $G_{2}$. 3. Mitotic/delayed mitotic death, where death occurred after one or more cell division. (6).

To investigate whether the sensitivity of leukaemias to chemotherapeutic agents depends on the abilities of leukaemia cells to respond to therapeutic insult by initiating apoptosis is an important task. In our work idarubicin was chosen as it is an anthracycline which is extensively used in the treatment of leukaemia's (10) and because it is less affected by P-glycoprotein expression (which can be responsible for cytostatic resistance) than other anthracyclines (2). Idarubicin also has the advantage of being available for oral administration, which is often appropriate for the treatment of elderly patients with AML and MDS, as part of combination treatment regimens. Idarubicin is a DNA intercalating agent, which interacts with topoisomerase II and has an inhibitory effect on nucleic acid synthesis. 
Variable response of malignant cells to cytostatic therapy could be explained first by proliferation status of these cells, second by the ability of the cytostatic to induce cellcycle arrest in a specified cell-cycle phase and third by the ability to induce apoptosis. In our work we analysed cell cycle status of HL-60 line, duration and intensity of cellcycle arrest and the ability of damage repair or apoptosis initiation after low-doses idarubicin treatment using flowcytometric DNA analysis.

\section{Materials and Methods}

\section{Cell culture and culture conditions}

Human leukaemia HL-60 cells were obtained from the European Collection of Animal Cell Cultures (Porton Down, Salisbury, UK) and were cultured in Iscove's medium (Sigma Inc.) supplemented with $20 \%$ fetal calf serum (FCS) in a humidified incubator at $37^{\circ} \mathrm{C}$ and controlled 5\% $\mathrm{CO}_{2}$ atmosphere. The cultures were divided every $3^{\text {rd }}$ day by dilution to a concentration of $2 \times 10^{5}$ cells $/ \mathrm{ml}$. Cell count was performed with a haemocytometer, cell membrane integrity was determined using the Trypan blue exclusion technique. HL-60 cells in the maximal range of 20 passages were used for this study.

\section{Cell treatments}

Exponentially growing HL-60 cells were suspended at a concentration of $2 \times 10^{5}$ cells $/ \mathrm{ml}$ in complete medium. 10 $\mathrm{ml}$ of aliquots were plated into $25 \mathrm{~cm}^{2}$ flasks (Nunc) and mixed with idarubicin (Zavedos, Pharmacia Upjohn S.p.A. Laboratories) at desired concentrations. After 4 hours idarubicin-containing medium was removed and replaced with fresh culture medium without idarubicin. Following 6, 24,48 and 72 hours the cells were counted and cell viability determined with the Trypan blue exclusion assay.

\section{Cell morphology}

For calculation of the percentage of cells showing morphology of apoptosis, aliquots were removed from control and drug-treated cell cultures at various times of incubation and usually 400 cells were counted on Diff-Quik (DADE BEHRING) stained cytospin preparations. Apoptotic cells were identified by the condensed and fragmented state of their nuclei and focal protrusions of the cell surface.

\section{Cell surface markers and cell size analysis}

Flow cytometry was used for cell surface antigen analysis and for apoptosis monitoring. Cells were washed twice with PBS containing 5\% FCS. Then, $1 \times 10^{5}$ cells were suspended in $0.5 \mathrm{ml}$ PBS with $5 \% \mathrm{FCS}$ and $0.02 \% \mathrm{NaN}_{3}$ and incubated with $\mathrm{mAb}$ APO2.7 for $30 \mathrm{~min}$ at $4^{\circ} \mathrm{C}$.

For apoptosis detection the mouse phycoerythrin (PE)conjugated mAb APO2.7 (clone 2.7 A6A3) (obtained from Immunotech) for detecting 7A6 antigen expressed by cells undergoing apoptosis has been used. We used this method without cell permeabilisation.
Flow cytometric analysis was performed on a Coulter Epics XL flow cytometr. A minimum of 10000 cells was collected for each sample in a list mode file format. List mode data were analysed using Epics XL System II software colour eventing (Coulter Electronic, Hialeah, FL, USA).

\section{Cell cycle analysis}

Following 6, 24, 48 and 72 hours of incubation, the cells were washed with cold PBS, fixed by $70 \%$ ethanol and stained with propidium iodide (PI) in Vindelov's solution for 30 minutes at $37^{\circ} \mathrm{C}$. Fluorescence (DNA content) was measured with Coulter Electronic, Hialeah, FL, USA apparatus. A minimum of 10000 cells analysed in each sample served to determine the percentage of cells in each phase of cell cycle, using Multicycle AV software. Three independent experiments were performed.

\section{Results}

\section{Cell growth and viability}

Fig. 1 shows the effects of idarubicin on the proliferative rate of HL-60 cell line. Cultivation with $5 \mathrm{nmol} / 1$ idarubicin induced high inhibition of the rate of HL-60 cell growth. The decrease of the proliferative rate observed in HL-60 cells after addition of higher concentration of idarubicin was observed. After 48 hours all cells with 100 and $50 \mathrm{nmol} / 1$ idarubicin were dead.

\section{Morphologic changes}

HL-60 cells were incubated in the presence 5, 10, 20, 50 and $100 \mathrm{nmol} / 1$ idarubicin for 72 hours. After 1, 6, 24, 48 and 72 hours cell morphology was examined on DiffQuik stained cytospin preparations. Morphologic evidence of apoptosis was found in cells treated with idarubicin. After addition of idarubicin dose dependent increase in the proportion of apoptotic cells was detected in cultures exposed to $5-100 \mathrm{nmol} / 1$ idarubicin. The maximal percentage of apoptotic cells was observed in cultures incubated for 6 or 24 hours treated with 100 or $50 \mathrm{nmol} / 1$ idarubicin respectively. (Fig. 2). During in vitro studies, where apoptotic cells cannot be removed by fagocytosis, secondary necrosis can be observed in later intervals ( 24 to 72 hours in Fig.2).

\section{Analysis of cell-cycle and sub-diploid DNA content}

We assessed DNA cleavage in the afore mentioned 5 and 10nmol/1 idarubicin-treated tumour cells. We have observed that after 6 hours of incubation most of the live idarubicin-treated cells were in S phase of cell-cycle (62\% or $71 \%$, respectively), after 24 hours most of them moved to $\mathrm{G}_{2}$ phase $(61 \%$ or $75 \%)$ and after 48 hours the percentage of cells in various cell-cycle phases was comparable to control untreated cells (Fig.3). Results of one representative experiment with idarubicin concentration $5 \mathrm{nmol} / \mathrm{l}$ are shown in Fig. 4. 
Fig. 1: Kinetics of idarubicin effect on the proliferative rate of HL-60 cell line. HL-60 cells were exposed to various idarubicin concentrations $(5-100 \mathrm{nmol} / \mathrm{l})$ for 4 hours and then cultivated in idarubicin-free medium. Number of viable cells was determined by Trypan blue staining.

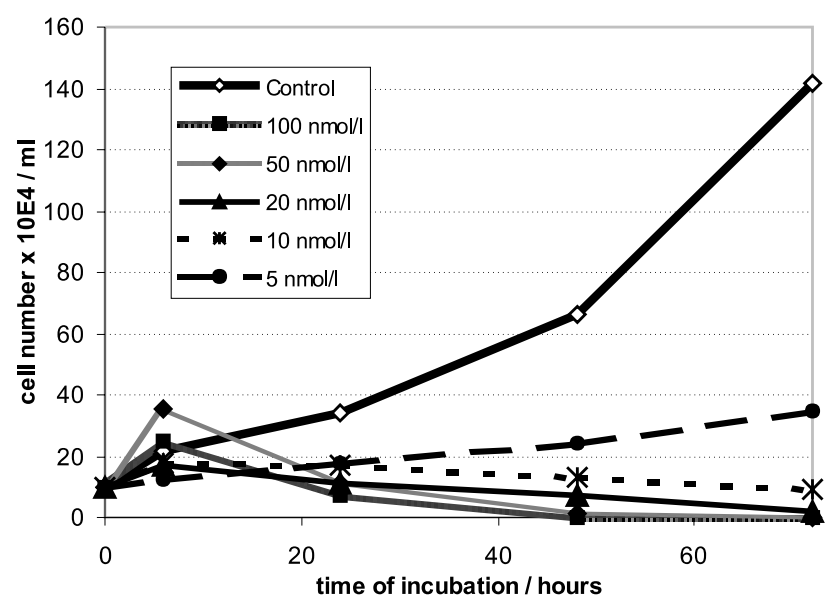

Fig. 2: Time course of apoptosis in HL-60 cells exposed to idarubicin as determined by cell morphology examined on Diff-Quik stained cytospin preparations. Data represent medium values from 3 independent experiments.

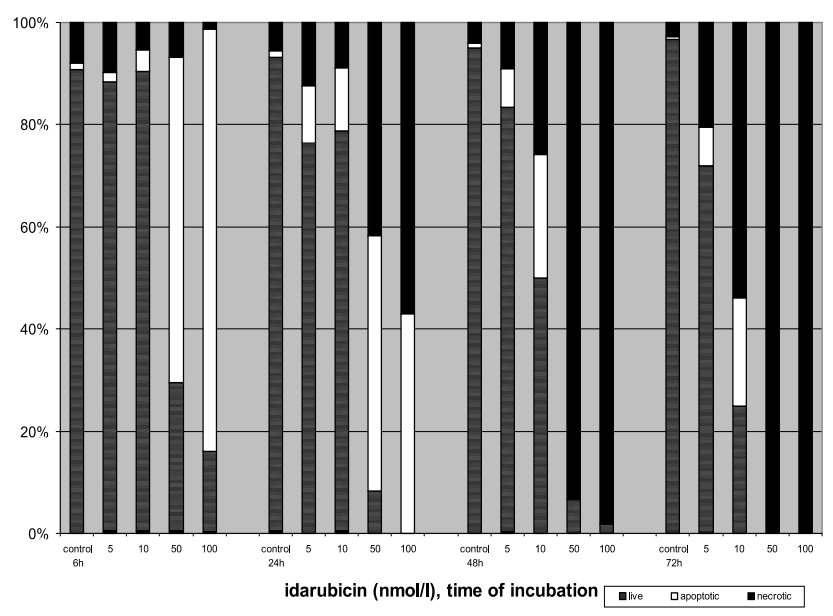

Fig. 3: Flow cytometric analysis of DNA content and cellcycle after treatment with 5 and $10 \mathrm{nmol} / 1$ idarubicin.

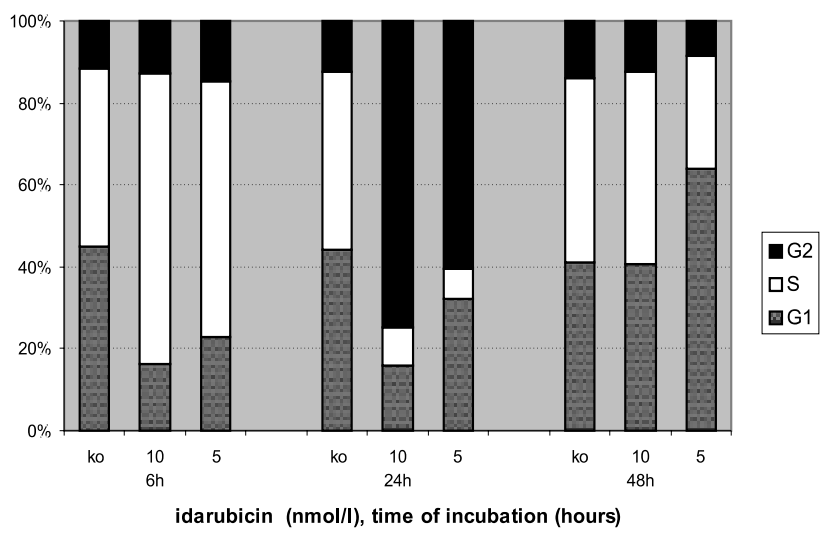

Fig. 4: Flow cytometric analysis of DNA content and cellcycle after treatment of HL-60 cells with $5 \mathrm{nmol} / 1$ idarubicin. Apoptotic cells are identified as cells with subdiploid DNA content (lower DNA content than cells in $\mathrm{G}_{0} / \mathrm{G}_{1}$ phase), i.e. subG $_{1}$ peak. Representative results for single experiment are shown.
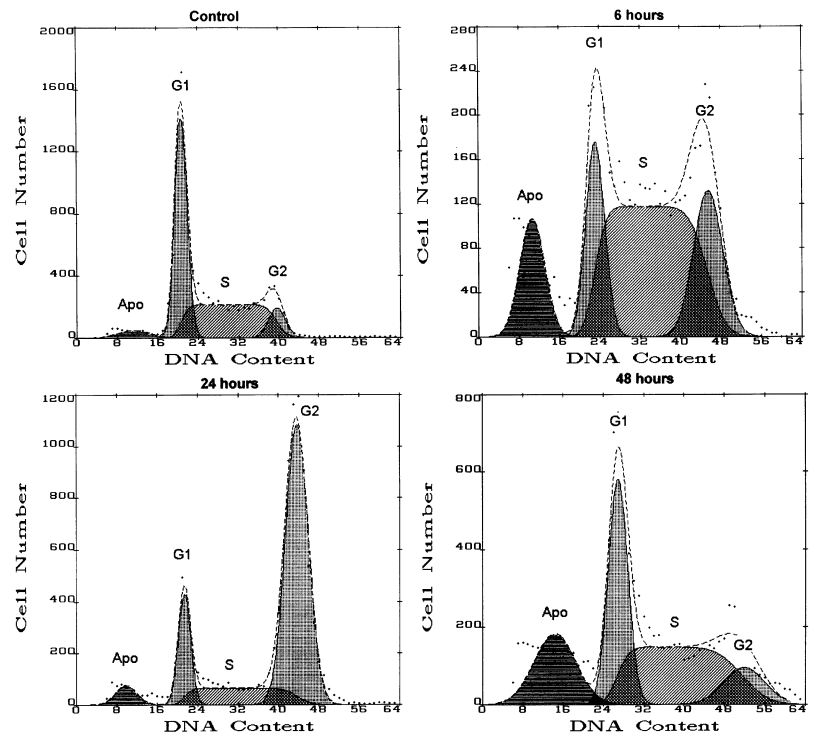

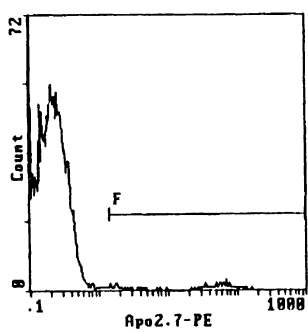

Control

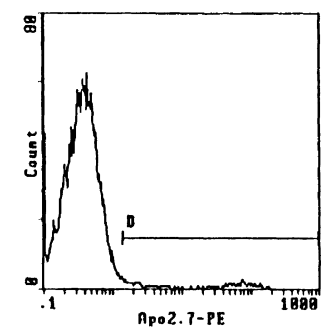

$6 \mathrm{~h}$

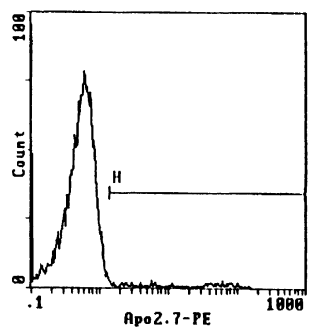

$24 \mathrm{~h}$

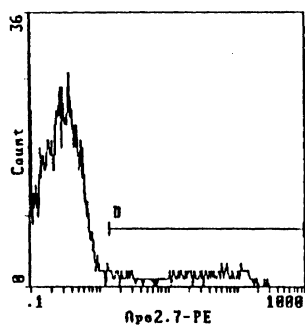

$48 \mathrm{~h}$

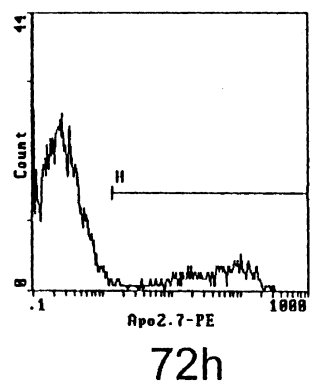

Fig. 5: Histograms for cell number versus APO2.7-PE fluorescence intensity of unprocessed HL-60 cells after treatment with $5 \mathrm{nmol} / \mathrm{l}$ idarubicin. Representative results for single experiment are shown. 


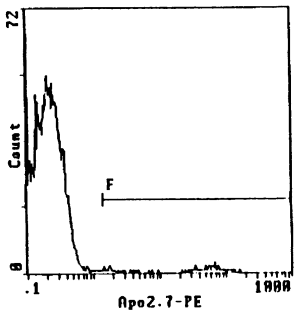

Control

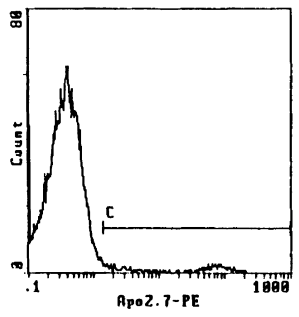

$6 \mathrm{~h}$

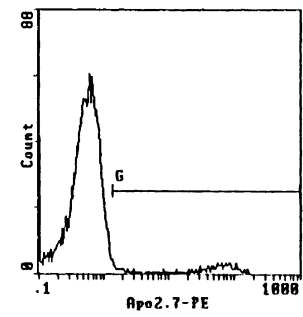

$24 \mathrm{~h}$

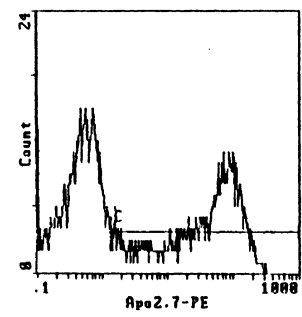

$48 \mathrm{~h}$

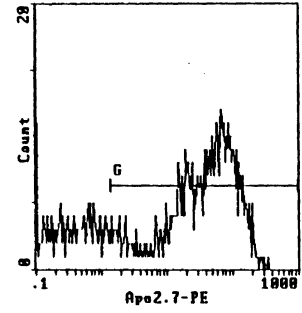

$72 \mathrm{~h}$

Fig. 6: Histograms for cell number versus APO2.7-PE fluorescence intensity of unprocessed HL-60 cells after treatment with $10 \mathrm{nmol} / 1$ idarubicin. Representative results for single experiment are shown.

\section{Flow cytometric detection of apoptotic cells using monoclonal antibody APO2.7}

Since 7A6 antigen is selectively expressed on the mitochondrial membrane in cells undergoing apoptosis, we attempted to detect apoptotic cells using APO2.7 monoclonal antibody after 5 and $10 \mathrm{nmol} / 1$ idarubicin treatment of HL-60 cells. As shown in Fig.5 in unpermeabilised cells APO2.7 antibody staining significantly increased from $6 \%$ at $6 \mathrm{~h}$ to $65 \%$ at $72 \mathrm{~h}$ after treatment with $10 \mathrm{nmol} / 1$ idarubicin, while increased only slightly after treatment with $5 \mathrm{nmol} / 1$ idarubicin (from $6 \%$ at $6 \mathrm{~h}$ to $16 \%$ at $72 \mathrm{~h}$ ) (Fig. 6 ).

\section{Discussion and Conclusions}

HL-60 line has amplified myc and activated ras oncogene, it is p53 negative and does not contain the characteristic $\mathrm{t}(15 ; 17)$ translocation seen in acute promyelocytic leukaemia $(3,4)$. HL-60 cells were negative for expression of CD34 and AC133 antigens (0.6/0.7\%), the antigens usually used for separation of haematological progenitors from mobilised peripheral blood patients for autologous transplantation. HL-60 cells expressed high levels of CD15 (93\%) and CD33 (84\%) antigens, 82\% cells were $\mathrm{CD} 5^{+} / \mathrm{CD} 33^{+}(5)$. Haematopoietic progenitor cells giving rise to monocytic and granulocytic lineages express numerous surface antigens to varying degrees depending on their developmental stage: CD33 antigen is expressed prior to myeloid commitment and CD15 is expressed at later stages in myelomonocytic development. Hofmanová et al. (3) described that $90 \%$ HL-60 cells were promyelocytes and $8 \%$ myelocytes with no expression CD14/CD11b antigens.

We show in this study that relatively high doses of idarubicin (50-100 nmol/1) induce as soon as after 6 hours in leukemic cell-line HL-60 cell shrinkage, membrane blebbing and cytoplasmic and nuclear fragmentation leading to the formation of apoptotic bodies, as determined by evaluation of Diff-Quik stained cytospin preparations using standard light microscopy at $1000 \mathrm{x}$ magnification, as well as by flow-cytometric analysis of cell DNA content. During apoptosis DNA becomes fragmented by endonucleases and these small DNA fragments can break out from the cells, resulting in a reduced total DNA content and hence a sub- $\mathrm{G}_{1}$ fluorescence peak representing apoptotic cells. Our re- sults show that high doses of idarubicin induce apoptosis soon after treatment ( 6 hours). We presume that the cells die by rapid interphase apoptosis, where the apoptosis is triggered in all phases of cell cycle. Some studies (8) suggest that apoptosis induction and $\mathrm{G}_{1}$ or $\mathrm{G}_{2}$ cell cycle arrest are two separate phenomenons in Jurkat cells (T-cell line, mutated gene TP53, undetectable levels of TP53 protein) It has been shown (in accordance with thesis that cells with mutated TP53 are radioresistant) that apoptosis occurs in these cells during 24 hours after irradiation by high doses of ionising radiation(10-20 Gy). Regardless of the cell cycle phase $20 \%$ of apoptotic cells have been detected 6 hours after irradiation dose 20 Gy. Apoptosis was lower when early $G_{1}$ subpopulation has been irradiated in comparison to other cell cycle phases. It seems that after irradiation of cells in $G_{1}$ phase apoptosis occurs 2 hours later in comparison with cells in other cell-cycle phases. However, 24 hours following irradiation by 20 Gy all cells were apoptotic regardless of the cell-cycle phase, in which they were irradiated.

Relatively lower doses of idarubicin (5-10 nmol/1) first inhibit proliferation of the cells and induce changes in cell cycle. We have observed that after 6 hours of incubation most of the live cells accumulate in $\mathrm{S}$ phase of cell-cycle, after 24 hours we observed arrest in $G_{2}$ phase. After $48 \mathrm{~h}$ following $10 \mathrm{nmol} / 1$ idarubicin treatment we observed significant apoptosis and the cells did not proliferate during 72 hours. Lower dose $(5 \mathrm{nmol} / 1)$ induces only small percentage of apoptosis after cell-cycle arrest in $\mathrm{G}_{2}$ phase and the cells slightly proliferate during 72 hours following idarubicin treatment. We suppose that after $10 \mathrm{nmol} / 1$ the cells die by delayed interphase apoptosis, which typically occurs after cell-cycle arrest in $G_{2}$ phase. Similar results have been reported after irradiation of HL-60 cells by 5-10Gy, where the apoptosis occurs following cell-cycle arrest in $G_{2}$ phase 36-48 hours after irradiation (9). Cell-cycle arrest in $\mathrm{G}_{2} / \mathrm{M}$ phase has been observed in Jurkat cells (8) following irradiation by relatively low dose $2 \mathrm{~Gy}$, regardless of cellcycle phase, in which they were irradiated. Apoptotic cells were cumulated 22-50 hours after irradiation. It is interesting, that apoptosis occurred sooner in population of cells irradiated in $G_{2}$ phase in comparison to other cell-cycle phases. 
It can be concluded that apoptosis induced by low doses of idarubicin in TP-53 negative cells HL-60 as well as apoptosis induced by ionizing_radiation in dose 2-10 Gy in various TP-53 negative haematopoietic cell lines (Jurkat, HL-60) occurs following $G_{2}$ cell-cycle arrest. Apoptosis was observed at HL-60 cells as soon as 6 hour after treatment with high idarubicin concentrations $(50-100 \mathrm{nmol} / 1)$, similarly to Jurkat cells irradiated by supralethal doses (10-20 Gy), which also underwent apoptosis after 6 hours. Syljuasen and McBridge (8) proved that Jurkat cells treated by ionizing radiation could undergo apoptosis independently on cell-cycle arrest and that period in which apoptosis is observed is related to the dose of radiation. Similar results result from our experiments on idarubicin influence on HL-60 cells.

\section{Acknowledgment}

This work was supported by grants from the Czech Ministry of Defence (MO66020398129) and from Grant Agency of Charles University (GA UK 279/98) and in part by research project J13/98: 111500001 .

\section{References}

1. Aldridge DR, Radford IR. Explaining differences in sensitivity to killing by ionizing radiation between human lymphoid cell lines. Cancer Res 1998;58:2817-
2. Berman E, McBride M. Comparative cellular pharmacology of daunorubicin and idarubicin in human multidrug-resistant leukaemia cells. Blood 1992;79(12): 3267-73

3. Hofmanová J, Kozubík A, Dušek L, Pacherník J. Inhibitors of lipoxygenase metabolism exert synergistic effects with retinoic acid on differentiation of human leukaemia HL-60 cells. Eur J Pharm 1998;350:273-84.

4. Kravtsov V, Fabian I. Automated monitoring of apoptosis in suspension cell cultures. Lab Invest 1996 (2);74:557-70.

5. Mareková M, Vávrová J, Vokurková D. Apoptosis in human HL-60 induced by ethanol. Gen Physiol Biophys 2000 (in press).

6. Radford IR, Murphy TK. Radiation response of mouse lymphoid and myeloid cell lines. Part 3. Different signals can lead to apoptosis and may influence sensitivity to killing by DNA double-strand breakage. Int J Radiat Biol 1994;65:229-39.

7. Schiffer CA, Dodge R, Larson RA. Long-term follow-up of Cancer and Leukaemia Group B studies in acute myeloid leukaemia. Cancer 1997;80(11 Suppl):2210-4.

8. Syljuasen, RG, McBride, WH. Radiation-induced apoptosis and cell cycle progression in Jurkat T cells. Radiat Res 1999;152:328-31.

9. Vávrová J, Mareková M, Vokurková D. Lidské hematologické nádorové linie a jejich citlivost $\mathrm{k}$ účinkům ionizujícího záŕení. Voj zdrav Listy 2000 (in press).

10. Wiernik PH, Banks PL, Case DC Jr et al. Cytarabine plus idarubicin or daunorubicin as induction and consolidation therapy for previously untreated adult patients with acute myeloid leukaemia. Blood 1992;79(2):313-9.

Submitted February 2000.

Accepted March 2000.

MUDr. Martina Mareková,

Charles University Prague, Faculty of Medicine Hradec Králové, Department of Medical Biochemistry, Šimkova 870, 50001 Hradec Králové, Czech Republic. e-mail: marekova@lfhk.cuni.cz 